\title{
LA MUJER COMO GENERADORA DE UNA NUEVA CULTURA. UNA LECTURA DIFERENTE DE LA COLONIZACIÓN ESPAÑOLA DE AMÉRICA
}

\author{
POR \\ María Antonia Bel Bravo \\ Universidad de Jaén (España)
}

\section{RESUMEN}

El traslado de la cultura española a los nuevos territorios americanos, con su importante carga evangelizadora, no se produjo de modo automático, ni mecánico.Atravesó distintos filtros, y uno de ellos fue el femenino. Este artículo pretende ser un reto para aquellos que deseen acometer el estudio de la inculturación de modo diferente al tradicional, más acorde con los nuevos parámetros historiográficos. ¿Más completo, quizás? El rol de la mujer en el matrimonio, en la familia, en la educación o en las labores de asistencia social durante el proceso de colonización -de lo que se ofrecen varios ejemplos- necesita, por ello, ser estudiado con mayor profundidad y abre nuevas perspectivas para la comprensión del continente americano bajo el dominio hispánico.

PALABRAS CLAVE: Mujeres, Inculturación, América, Evangelización.

\section{WOMEN AS GENERATING A NEW CULTURE. A DIFFERENT READING OF THE SPANISH COLONIZATION OF AMERICA}

\section{AbSTRACT}

The Spanish culture transfer to the new American territories -with its significant evangelizing burden- did not happen in an automatic nor mechanical way. It passed through different filters, one of them was femenine. This article is intended to be a challenge for those wishing to undertake the study of inculturation in a different way to that of the traditional way, more towards keeping with the new historiographic parameters. More complete, perhaps? Role of the woman in the marriage, in the family, in the education or in the social assistance during the 
process of colonisation (of what the article offers several examples) needs, thus, be studied with greater depth and, of course, opens new perspectives for the understanding of the American continent during the Spanish command.

KEY WORDS: Woman, Inculturation, America, Evangelisation.

Recibido/Received 2010-05-04

Aceptado/Accepted 2011-06-23

Siempre es conveniente convertir el destino en oportunidad. ¿Qué quiero decir con esto? Sencillamente que si la mujer durante siglos estuvo relegada, esta postergación, o como queramos llamarla, para algunas fue un infierno y para muchas un reto que había de sortearse creativamente. Me explico: el traslado de la cultura española a los nuevos territorios descubiertos en América no se produjo de forma automática, ni mecánica. Atravesó distintos filtros (monárquico, religioso, etc.) y uno de ellos fue el femenino.

¿Qué hacer para evitar que la experiencia femenina careciera de voz, quedase muda? ¿Qué hacer para hacer cultura con la experiencia y los saberes de las mujeres? ¿Qué hacer para apoyar la libertad de las niñas, de las adolescentes y jóvenes de los nuevos territorios descubiertos? Seguro que había muchas cosas por hacer. Pienso que una de ellas fue que las mujeres ofrecieran a las indígenas genealogía femenina, que les permitiera no perder el origen, la raíz que las mantuviera unidas a sí mismas, a la realidad tradicional y a la nueva, a la española; para que, como decía María Zambrano, la realidad no las engullera, no las aplastara.

Para una niña, para una mujer, la ausencia de genealogía femenina en la que arraigar, en la que apoyarse, supone un riesgo que no se puede correr. Porque, «aprender en la escuela el conocimiento hecho a la medida del ser hombre y no (o muy poco) el conocimiento hecho a la medida del ser mujer, no es sólo una cuestión cuantitativa o de erudición. Es una cuestión del orden simbólico, ${ }^{1}$ o sea, afecta al sentido de la vida y de las relaciones (que es el asunto fundamental de la existencia humana), porque tiene consecuencias importantes en la independencia simbólica de ser mujer». ${ }^{2}$

Así pues, a las mujeres se les encomendó en buena medida -como en todos lados- la tarea de educar, pero no sólo de manera oficial -también, como en todos lados, ésta la ostentaban principalmente los varones-, sino informal, extraacadémica podríamos decir, y esto les permitió un margen bastante amplio de originalidad.

La influencia de la realidad local americana, con sus riquezas y sus carencias, se impuso, casi siempre, sobre pretendidos idealismos humanistas o ilus-

\footnotetext{
${ }^{1}$ Muraro, L.: «Autoridad sin monumentos» en Duoda. Revista de estudios feministas, $\mathrm{n}^{\circ}$ 7, 1994 , pp. 86-100.

${ }^{2}$ Rivera, M. M.: Juana de Mendoza. Ediciones del Orto, Madrid, 2004, p.21. 
trados y bienintencionadas disposiciones reales. Así pues, al mismo tiempo que se desarrollaba la cultura oficial hispánica y académica, patrimonio de grupos reducidos, esencialmente masculinos, se enriquecía la cultura popular, mezcla de tradiciones indígenas y religiosidad cristiana, de manifestaciones estéticas locales y elementos importados de la cultura material europea, esencialmente femenina.

La necesidad de hacer visibles los saberes de las mujeres tiene que ver con un criterio de realidad, de verdad, que es el que lo exige. El mundo es uno y los sexos son dos; a esa evidencia corresponde que el conocimiento, los saberes, los modos de estar en el mundo se expresen siempre a dos voces, en masculino y en femenino. ${ }^{3} \mathrm{La}$ incapacidad del simbólico patriarcal de aceptar esa evidencia conduce (en el mejor de los casos a la confusión y al empobrecimiento y (en el peor) al error, a vivir en una fantasía inexistente. Así que nombrar el mundo en femenino y en masculino es una exigencia epistemológica.

Mucho se ha hablado y escrito sobre la participación del hombre, del caballo, incluso del perro en la conquista del Nuevo Mundo. Muy poco se ha escrito, no obstante, de la participación de la mujer, y de su importantísima labor en el descubrimiento, colonización y evangelización de las nuevas tierras. Este factor ha sido ignorado por muchos historiadores que han querido ver en la conquista de América un hecho exclusivamente masculino, sin darse cuenta de que en la mayor parte de las expediciones y asentamientos posteriores las mujeres jugaron un papel de primer orden.

En opinión de Juan Maura, «la única razón de excluir a las mujeres en el panorama general de la conquista tiene una relación directa con la Leyenda Negra. El querer presentar a los españoles como un puñado de hombres cuyo último fin era saquear a los indígenas de todas sus riquezas, especialmente su oro, para marcharse una vez destruidas las culturas conquistadas, no dejaba cabida a la imagen de la mujer». ${ }^{4}$

No obstante, el empleo de las plantas medicinales locales, las alhajas de las mujeres criollas, las flores que adornaban sus cabellos, la decoración de sus salones y las vasijas de sus cocinas fueron testimonio del contacto entre ambas culturas, como también lo fueron los bordados y chales de las mujeres indias, los bailes populares, las devociones y peregrinaciones, etc. Hacer visibles, darles valor a las experiencias y los saberes que las mujeres han llevado y llevan al

\footnotetext{
${ }^{3}$ Rivera, M. M.: La diferencia sexual en la Historia, Publicaciones de la Universidad de Valencia, Valencia, 2005.

${ }^{4}$ Maura, J.: «Mujeres hispanas en la conquista del Nuevo Mundo: a la vanguardia de los acontecimientos», 1995 en Revista de Estudios Hispánicos 22: 188. El autor critica la visión anglosajona de la conquista española de América, atribuyéndole una gran parte de la responsabilidad de la Leyenda Negra que ha recaído sobre España.
} 
mundo y a la educación es reconocer autoridad femenina y eso fue lo que hicieron muchas mujeres en América, tanto indígenas como españolas.

\section{EL MARCO OFICIAL DE LA EVANGELIZACIÓN}

Sin embargo, la colonización americana, al igual que la filipina, ofrece una estructura y unas características generales que le son propias dentro del marco histórico de las misiones católicas. Ambas facetas se derivan de tres factores fundamentales, consistentes en el especialísimo papel que la Corona española desempeñó en el proceso evangelizador, en las también especialísimas circunstancias en las que se desarrolló ese mismo proceso y en las particularidades que ofreció el mundo americano, sobre todo el de las sociedades indígenas prehispánicas.

Las relaciones de la Corona española con la evangelización del Nuevo Mundo arrancan, como sabemos, de la Bula Inter Coetera de 3 de mayo de 1493, por la que el papa Alejandro VI, tras recoger el deseo y la promesa expresados por los Reyes Católicos en este sentido, les impone la obligación de enviar a las islas y tierras nuevas descubiertas «varones probos, temerosos de Dios, doctos, instruidos y experimentados», para que convirtieran al cristianismo a los indígenas recién conocidos.

El precepto evangelizador, impuesto a los reyes españoles, era un requisito conforme a la tradición bajomedieval reflejada en los casos de las Canarias y de las exploraciones portuguesas en el litoral occidental africano. Entrañaba, en cambio, la novedad de que confíaba expresamente a la Corona Española el derecho y la obligación de enviar misioneros a América, a diferencia de los documentos pontificios anteriores, en los que no se especificaba cómo se debería realizar la cristianización de las tierras que se descubrieren u ocuparen.

A esta inicial obligación, restringida al envío de un personal misionero que en principio no era incumbencia de la Corona, se le fueron añadiendo paulatinamente el derecho y las obligaciones anejos a los sistemas de Patronato Real, ${ }^{5}$ del Vicariato Regio y del Regalismo borbónico para que la Corona terminara asumiendo prácticamente todas las facultades y deberes exigidos para la propagación del Evangelio.

No transcurriría demasiado tiempo para que la emperatriz Isabel y algunas otras personas se dieran cuenta de que eran necesarias también «mujeres probas».

\footnotetext{
${ }^{5}$ Estos conceptos están explicados en la obra de Borges, P. 1992 Historia de la Iglesia en Hispanoamérica y Filipinas. 2 vols. Madrid, BAC.

Hispania Sacra, LXIV

129, enero-junio 2012, 211-235, ISSN: 0018-215-X, doi: 10.3989/hs.2012.007
} 
Como ya dijo con sabiduría la mística medieval, «cada cosa se aprende con su igual», así que si queríamos apoyar la libertad de las niñas debíamos tener en cuenta que ésta «no se alcanza estancándose en la opresión y en la miseria sino, solamente, con la libertad». ${ }^{6}$ Era preciso, pues, enseñar con ejemplos de libertad femenina, de mujeres que (a veces, sin conciencia plena de la trascendencia de lo que han hecho) han sido fieles a sí mismas y han buscado el sentido en sí y en otras, sin copiar ni repetir los modos masculinos.

Por tanto, el papel de la mujer en América va a tener una importancia singular ya que las indígenas fueron algunos de los más eficaces agentes del mestizaje étnico y cultural porque, entre otras cosas, supieron utilizar el vehículo por antonomasia: la lengua.

\section{LA LENGUA Y LA AUTORIDAD FEMENINA}

El emperador, en 1550, insistía en la conveniencia de introducir la lengua castellana, sin llegar a imponerla como obligatoria para los indios, sino limitándose a dar facilidades a quienes voluntariamente deseasen aprenderla. Pocos años después, las recomendaciones de los misioneros sobre las ventajas de la extensión del nahuatl, lograron convencer al virrey don Luis de Velasco, a los miembros del Consejo de Indias y al rey Felipe II, de la conveniencia de extender el nahuatl hacia los lugares en que la diversidad y dificultad de las lenguas retrasaba la evangelización.

Pese al gran interés que los evangelizadores tenían por cristianizar en lenguas vernáculas, en muchas ocasiones necesitaron emplear las «lenguas»o intérpretes nativos, que previamente habían aprendido el español. Por tanto, el intercambio lingüístico está presente desde los inicios del proyecto español en América. La característica de español culto viene dada precisamente porque eran religiosos de cierta talla intelectual quienes en mayor medida contribuyeron a la difusión de nuestro idioma por tierras americanas.

Mientras se discutían las ventajas teóricas de evangelizar en nahuatl, en castellano o en las múltiples lenguas locales, las mujeres indígenas, como nanas de los niños criollos o mestizos colaboraban eficazmente para lograr una mejor comunicación entre los habitantes de la Nueva España. Encargadas del cuidado de los hijos de familias acomodadas, de forma espontánea, les enseñaban su propia lengua. De la misma manera, la urgente cristianización recomendó que las doctrinas y beneficios eclesiásticos se mantuvieran en manos de los clérigos naturales de la región, únicos conocedores de las lenguas habladas en ella, argumentando que «como las indias los crían y enseñan sus lenguas desde la niñez,

\footnotetext{
${ }^{6}$ Ibid.
} 
las saben bien». ${ }^{7}$ De este modo los criollos fueron adquiriendo protagonismo en uno de los objetivos más importantes de la actividad española en América: la evangelización.

Ellas, las nanas, las más de las veces sin saberlo, actuaron de hecho como notables mediadoras entre la cultura hispánica y la indígena, es decir fueron creadoras de una nueva cultura, pues a fines del siglo XV los españoles se enfrentaron a lo nuevo, a lo desconocido. No sabían nombrarlo porque tampoco sabían definirlo, ni siquiera aislarlo de otras realidades conocidas; y se sirvieron de estas para aproximarse conceptual y verbalmente a lo primero. Para este proceso de apropiación sirven los indigenismos: con ellos se nombran realidades nuevas. Al poco tiempo ya serán voces españolas. Así, de forma paralela al mestizaje étnico, se da un trasvase verbal que dota de una lengua común a todo el territorio conquistado, contribuye a la expansión de unas pocas lenguas naturales, al tiempo que indianiza la lengua de los españoles: el mestizaje cultural. La comunicación se convierte en un camino de ida y vuelta.

\section{MATRIMONIO, AMOR Y MESTIZAJE}

La lengua fue el vehículo, pero vehículo ¿de qué y para que? Para muchas cosas, pero yo me voy a detener en una que reviste doble cara: el amor. El amor como leiv motiv de la evangelización y el amor como eje vertebrador del mestizaje matrimonial. En la práctica ambas cuestiones se funden en muchas ocasiones. Pero hagamos un breve inciso acerca de este tema del amor, ya que muchos elementos y falsas tradiciones han coincidido en una forma de pensar que considera el tema afectivo como algo un tanto secundario. Quizás gran parte del problema esté en la desafortunada identificación de la objetividad con una actitud de exploración, presuntamente neutral. La cuestión es que la afectividad en cuanto tal ha gozado de un descrédito generalizado. Un cierto desconocimiento de la persona es también sin duda el causante de que los afectos hayan pasado inadvertidos para las principales corrientes historiográficas. Veamos más detenidamente este asunto.

¿Por qué la afectividad humana tiene un papel secundario en la historia de las ideas y, en general, de los acontecimientos? ¿Por qué a veces dividimos a las personas únicamente desde el criterio de si son o no inteligentes, y nos olvidamos de otra división también muy interesante que hace referencia a su capacidad de sentir?: las personas no sólo se entienden, también se quieren, y tal vez porque se quieren llegan a entenderse. Pero esto no todos los investigadores lo aceptan, porque la hermenéutica de los afectos es a veces tan complicada que

${ }^{7}$ Consulta del Consejo de Indias. Madrid 20 de junio de1596, en Konetzke. 1953: 38-40.

Hispania Sacra, LXIV

129, enero-junio 2012, 211-235, ISSN: 0018-215-X, doi: 10.3989/hs.2012.007 
muchos prefieren ignorarla o menospreciarla, como ha señalado acertadamente Von Hildebrand. ${ }^{8}$

Además de una errónea igualación de sentimientos -corporales, emocionales o pasionales con la afectividad en general-, muy distintos entre sí, el motivo fundamental del descrédito que conlleva este tema, se produce por haber separado la experiencia afectiva del objeto que la motiva. La experiencia afectiva real es siempre intencional: se experimenta el sentimiento por algo y no se trata de sentimientos corporales cuando se habla de afectividad. El hecho de que lo que es importante en sí mismo sea capaz de movernos, produce una unión con el objeto mayor que la del conocimiento. Y es que en el amor, la unión que establece toda la persona con el objeto es más intensa que la que se pudiera dar con el sólo conocimiento.

Estos temas interesan a la «nueva» historia cultural, ${ }^{9}$ por ejemplo cuando se ocupa de la historia de la familia y, en general, de la inculturación. Pero más allá de estas leyes, los indígenas pensaron que los conquistadores por su aspecto y el lugar de donde venían - «dioses deben ser, que vienen de donde el sol nace»-10 eran imagen del Creador. Si tenemos en cuenta que además de esto la religión que predicaban era de amor y no implicaba sacrificios humanos... estaba cantada su pronta conversión al cristianismo y fomentaron la unión de sus mujeres con los recién llegados. Es bien conocido el pasaje de Bernal ${ }^{11}$ en el que los indígenas dijeron a Cortés que «pues éramos ya amigos, que nos quieren tener como hermanos, que será bien tomásemos a sus hijas y parientes para hacer generación». Les interesaba mezclar su sangre con el hombre blanco cuya divinidad se aceptaba para pactar firmes alianzas y lograr las virtudes del hombre «barbado».

Así pues, el elemento creador de la conquista española es la presencia humilde, pero penetrante, del amor cristiano. Otros europeos explotaron y asesinaron a los indígenas tanto y más ${ }^{12}$ que los españoles y durmieron con sus mujeres. Pero sólo el español al cruzarse con la india y amarla, comenzó a vivir espiritualmente con ella hasta que sus vidas crecieron juntas. «El español supo que había hecho una cristiana de la india, y que su hijo sería cristiano y súbdito del rey». ${ }^{13}$

\footnotetext{
${ }^{8}$ Véase El Corazón. Madrid, ediciones Palabra, 1997.

${ }^{9}$ Olábarri Gortázar, Ignacio y Caspistegui, Francisco Javier, dirs.: La «nueva» historia cultural la influencia del postestructuralismo y el auge de la interdisciplinariedad. Madrid, Complutense. Actas de curso de verano, celebrado en 1995.

${ }^{10} \mathrm{El}$ cronista Herrera es el autor de estas palabras, que recoge F. Morales Padrón en su libro Los conquistadores de América, Madrid, Austral, 1974, p. 166.

${ }^{11}$ Díaz del Castillo, B.: Historia verdadera de la conquista de la Nueva España. Madrid, Historia $16,1984$.

${ }^{12}$ Es interesante contrastar la colonización católica con la protestante y en este sentido se puede ver Messori, V.: Leyendas Negras de la Iglesia. Barcelona, Planeta, 2000.

${ }^{13}$ Waldo Frank: América Hispana. Buenos Aires, 1950, p. 68.
} 
En este sentido, desde 1503 la Corona Española dictó normas que favorecían los enlaces mixtos; recomendaban que «algunos cristianos se casen con algunas mujeres yndias, e las mugeres cristianas con algunos yndios, por lo que los unos e los otros se comuniquen e enseñen». ${ }^{14}$ Nuevas Reales Cédulas de 1514 y 1521, insistieron en lo mismo; pero mayor eficacia tuvo la disposición relativa a las encomiendas, que en el año 1539 exigía a los encomenderos solteros que contrajesen matrimonio. Por salvar sus bienes y a falta de mujeres españolas, fueron muchos los encomenderos que se casaron con la que convivían.

De esta forma, los españoles y sus mujeres indias establecieron los primeros núcleos familiares que reflejaban la nueva cultura híbrida que comenzaba a surgir, y ellas fueron las conservadoras de los valores culturales de ambos pueblos.

A las niñas se les permitiría tener una visión más adecuada y más realista del mundo, del conocimiento y de otras formas de relacionarse con él; formas no basadas en la fuerza y el poder sino en el reconocimiento y la confianza, en el amor. Conocer y reconocer los saberes de las mujeres les podría permitir a los niños y a los hombres aprender de ellas, de lo que estimen que es valioso, y, sobre todo, les podría dar un referente de alteridad, que está a su lado, que no es carente, ni dependiente, ni en relación de jerarquía, pero que tampoco los quiere desplazar, ni quitarles nada. Lo que sería un hallazgo revolucionario para la convivencia, en el aprendizaje siempre difícil del vivir bien consigo y con las y los demás. ${ }^{15}$

LA FAMILIA

Como señala Josefina Muriel, «aunque las mujeres no fueron quienes marcaron los lineamientos básicos del pensamiento novohispano, ni ocuparon los puestos públicos ni intervinieron directamente en la política, fueron las activas transmisoras de los valores culturales que constituyeron su mundo, esos que todavía llegan a nosotros tan hondamente como penetran en el alma las aguas del bautismo». ${ }^{16}$

Ellas son, por tanto, a través de la educación reglada y no reglada, las verdaderas sintetizadoras de dos culturas diferentes, ambas con raíces profundas en sus propias tradiciones. A raíz del choque étnico y cultural, las mujeres adquirieron importancia como refundidoras de viejas tradiciones e impulsoras de novedades generadas por los problemas que planteaba la vida cotidiana. Las indígenas conservaron hábitos y culturas domésticas prehispánicas, como ha

\footnotetext{
${ }^{14}$ Instrucciones dadas por los Reyes Católicos al gobernador Nicolás de Ovando en marzo de 1503, en Konetzke, 1946, pp. 215-216.

${ }^{15}$ VV. AA.: Las mujeres cambian la educación. Narcea, Madrid, 2008. Pág. 155.

${ }^{16}$ Muriel, op. cit., p. 9. 
señalado una de las pioneras en estas investigaciones ${ }^{17}$ y las españolas aportaron sus propias costumbres. Unas y otras tradiciones impregnaron la vida de las tierras americanas de un peculiar carácter mestizo, muy diferente de cuanto los españoles habían dejado al otro lado del océano. El habla popular, el vestido, la alimentación, algunas prácticas curativas y el orden doméstico-familiar mostraban claros rasgos de su raigambre americana. Y cuestiones que parecen únicamente relacionadas con el marco familiar se van a proyectar, a través de la mujer, a toda la sociedad.

¿Por qué? Porque en las sociedades preindustriales la familia era una manera de subsistir ${ }^{18}$ sus formas predominaban en las estructuras organizativas artesanas y empresariales, prevalecían el taller familiar y el trabajo doméstico, entre otras cosas porque la propia economía tampoco exigía más. El traspaso de los bienes se llevaba a cabo, en gran medida, mediante la dote y los sistemas de herencia, esto es, por cauces relacionados con la familia. Esta desempeñaba un papel de primera importancia en el mantenimiento de un orden social cuya jerarquía parece depender, entre otros principios, del respeto hacia los mayores y los antepasados. ${ }^{19}$

Por esto -y mucho más que no señalo, ya que no viene al caso- ${ }^{20}$ la familia gozó de una importancia singular durante la época moderna: es la célula básica de la sociedad, y la constitución de ésta, incluida su naturaleza política, es una proyección analógica de la relación familiar. Así lo hicieron ver constantemente los tratadistas de la época. Esta conclusión de la filosofía perenne se percibe con claridad en las obras del momento: la familia se entiende como el pilar más importante del Estado Moderno o, si se prefiere, el Estado como una suma de familias, correspondiendo a la autoridad del monarca su justo gobierno, como al cabeza de familia el del grupo doméstico.

Así pues, el desarrollo de la estructura familiar americana se sustentó tanto en la experiencia india como en la europea. Los indios civilizados se regían por criterios similares y definían los papeles familiares de modo muy semejante a como lo hacían los colonizadores. Ambos compartían un fuerte sentido del

\footnotetext{
${ }^{17}$ Muriel, J.: Cultura femenina Novohispana. México, UNAM, 2000. Véase también Lavrin, A. Historia de las mujeres latinoamericanas, México, Siglo XXI, 1994.

${ }^{18}$ Cf. Herlihy, D.: «Avances recientes de la demografía histórica y de la historia de la familia», en en VV. AA.: La Historiografía en Occidente desde 1945. Actitudes, tendencias y problemas metodológicos. Pamplona, EUNSA, 1985, pp. 223-245. La «reconstrucción de familias», ideada por Louis Henry, se ha considerado normalmente un método específico de la demografía histórica, pero lo cierto es que desde el comienzo demostró ser una clave muy valiosa para la comprensión científica de la función reproductora desempeñada por las familias. De ahí que la demografía histórica y la historia de la familia hayan sido campos complementarios, influenciados mutuamente. Véase Louis Henry: «Une richesse démographique en friche: les registres paroissiaux», en Population, VIII (1953), pp. 281-290.

${ }^{19}$ Véase James Casey, Historia de la familia, Valencia, 1983, cap. 2.

${ }^{20}$ Véase en Bel Bravo, M. A.: La familia en la Historia. Madrid, Encuentro, 2000.
} 
linaje, la creencia en la supremacía masculina y cierta preferencia por una estructura familiar cerrada y rodeada por una amplia red protectora de relaciones de parentesco.

Las familias ampliaban sus alianzas a través del lazo cuasisagrado del compadrazgo. Por lo general se pedía a parientes o amigos influyentes que aceptaran ser padrinos de los hijos, con lo cual adquirían obligaciones sociales y religiosas con sus ahijados y, en consecuencia con los padres de estos. Las familias de modesta condición solicitaban de quienes gozaban de rango y fortuna tales apadrinamientos, lo que les permitía relacionarse con gente de renombre y convertirse en sus clientes. Como señala Guerra, «Parentesco de origen religioso que fue sancionado por el impedimento matrimonial llamado de afinidad o parentesco espiritual, el compadrazgo tomó en la Europa meridional, y particularmente en los países mediterráneos, una importancia considerable, que vuelve a encontrarse acrecentada, en la Hispanoamérica. Parentesco voluntario en su origen, pero parentesco real después, el compadrazgo viene a menudo a reforzar lazos ya existentes de amistad, de intereses y de clientela». ${ }^{21}$

Una alianza menos formal, pero igualmente funcional, existía entre los paisanos, es decir aquellos procedentes del mismo lugar. Los grupos de inmigrantes españoles tenderán a formar familias con los procedentes de su misma región española. Aunque es preciso señalar que por si solo no es un indicador suficientemente válido, sirvió a Hirshberg ${ }^{22}$ para modificar una afirmación -considerada válida hasta el momento- respecto a la procedencia geográfica de los primeros habitantes de Puebla de los Ángeles.

La importancia de la familia, y la debilidad de otras instituciones no daban cabida en la sociedad americana al individuo aislado. Incluso los hombres solteros, al igual que los sacerdotes y las monjas, actuaban como miembros de familias extensas. Las únicas instituciones de cierto peso, además de la familiar, eran el Consulado, los gremios artesanales y las cofradías auspiciadas por la Iglesia. Sin embargo, incluso en estas agrupaciones resultaban decisivos los lazos de parentesco, ya que a menudo su formación se efectuaba alrededor de miembros de familias prominentes y sus partidarios. Aquellos desdichados que carecían de nexos familiares se convertían en verdaderos proscritos que vivían en la marginación: vagabundos, prostitutas alcohólicos, etc.

Así lo entendía Tomás Moro en Utopía, ${ }^{23}$ llegando incluso a considerar el

\footnotetext{
${ }^{21}$ Francisco Javier Guerra: México: del Antiguo Régimen a la Revolución, t. I. México, FCE, 1982, p. 130 .

${ }^{22}$ Véase este asunto en Julia Hirschberg: «Social experiment in New Spain: a prosopographical study of the early settlement at Puebla de los Ángeles 1531-1534», en Hispanic American Historical Review, vol. 59, $\mathrm{n}^{\circ} 1,1979$.

${ }^{23}$ Con otro título apareció en Lovaina, 1516, y definitivamente en Basilea, 1518. Ed. P. Rodríguez Santidrián, Madrid, Alianza, 1988, p. 136.
} 
conjunto de la república como una familia a gran escala. Jean Bodin ${ }^{24}$ recoge la misma idea. Para el magistrado francés, de igual manera que «la administración doméstica es el recto gobierno de varias personas y de lo que les es propio, bajo la obediencia de un cabeza de familia», la «República es un recto gobierno de varias familias, y de lo que les es común, con poder soberano». En este sentido, la familia «constituye la verdadera fuente y origen de toda república, así como su principal elemento (...) Al igual que la familia bien dirigida es la verdadera imagen de la república, y el poder doméstico es comparable al poder soberano, así, el recto gobierno de la casa es el verdadero modelo del gobierno de la república».

En España, y sin duda por influencia de Bodin, las ideas al respecto vienen a ser las mismas. Por ejemplo, según el licenciado Martín González de Cellorigo, la república «es un justo gobierno de muchas familias y de lo común a ellas con suprema autoridad» ${ }^{25}$ De ahí la importancia atribuida a la vida familiar, desde donde deben ponerse en marcha los remedios que logren la restauración de España y los territorios hispánicos, en una relación vertical familias-estado. Por esto Cellorigo exhortaba a la nobleza para que impusiera el cumplimiento de las leyes en el seno de sus propias familias, con lo cual darían ejemplo al resto del pueblo. ${ }^{26}$

\section{ESPACIOS DE LIBERTAD A TRAVÉS DE LA EDUCACIÓN}

Toda la Historia apunta al hecho de que es el ser humano y no la naturaleza quien proporciona los recursos primarios, que el factor clave de todo desarrollo económico proviene de la mente del hombre. La realidad es que, de repente, hay una explosión de fuerza, de iniciativa, de creatividad, que no se sabe muy bien de donde viene: es la educación, el más vital de los recursos y llave de todas las cosas.

La tarea de la educación debería ser, antes que cualquier otra cosa, la transmisión de criterios de valor, de qué hacer con nuestras vidas. Sin duda también hay necesidad de transmitir el «saber cómo», pero esto debe estar en un segundo plano porque primero se ha de tener una idea razonable de qué hay que hacer. La esencia de la educación, pues, es la transmisión de valores porque cuando la gente pide educación lo que normalmente quieren decir es que necesitan algo más que entrenamiento, algo más que el mero conocimiento de los hechos. Lo

${ }^{24}$ Los seis libros de la República, París, 1576. Ed. P. Bravo Gala, Madrid, Tecnos, 1985, caps. I-II, pp. 9-19.

${ }^{25}$ Martín González de Cellorigo: Memorial de la política necesaria y útil restauración a la república de España y estados de ella, y del desempeño universal de estos reinos, Valladolid, 1600. Ed. José Luis Pérez de Ayala, Madrid, Instituto de Estudios Fiscales, 1991, p. 63.

${ }^{26}$ Ibid., p. 99. 
que buscan son ideas que les presenten el mundo y sus propias vidas de manera inteligible porque vivir es hacer una cosa en lugar de otra. ¿Qué es entonces la educación? Es la transmisión de ideas que le permitan al hombre elegir entre una cosa u otra. En este sentido, la autoridad femenina es necesaria para las mujeres por su papel referencial. ¿Por qué hacer visibles y dar valor a los saberes de las mujeres? Porque no hay autoridad sin adjetivación.

¿Están en la escuela pero no aprenden sobre sí mismas sino sobre el mundo hecho a la medida de los hombres? ¿Enseñan las maestras y los maestros un conocimiento adecuado para las niñas, esto es, un conocimiento que recoja las aportaciones y el modo de estar en el mundo de las mujeres? Para una mujer, el pasaje a la libertad es el sentido libre de su diferencia, como mujer y como ella tomada en singular, las dos cosas a la vez. Sentido libre significa que ella misma, en relación con las demás, en el contexto en el que vive con los recursos de la lengua materna, intenta leer su experiencia, orientarse en el mundo y actuar en él.

Muraro $^{27}$ entiende la autoridad femenina como una figura de intercambio no como una categoría; un referente que nos da sustento simbólico, sentido y lugar en el mundo, en el que otra mujer en quien se confía te ayuda a mirar y medirte con la realidad. La ciencia no puede producir ideas que nos sirvan para vivir. Si alguien busca educación porque se siente perdido, porque su vida le parece vacía y sin sentido, no podrá obtener lo que va buscando por el estudio de cualquiera de las ciencias naturales; en otras palabras por el «saber cómo». Ese estudio tiene mucho valor pero no soluciona nada a nuestra protagonista. Deberá dirigirse a las llamadas Humanidades, pues sólo ahí podrá encontrar respuestas para sus preguntas vitales. Son muchas las ideas que pueden proporcionarle las Humanidades por su carácter de esencialidad y universalidad.

Una educación meramente científica no puede hacer esto porque trata sólo con ideas instrumentales, mientras que lo que se necesita es la comprensión de por qué las cosas son como son y que es lo que tenemos que hacer con nuestras vidas: necesitamos las ideas grandes y vitales de nuestro tiempo. Esto no quiere decir que en las Humanidades no nos encontremos con academicismos y tópicos que constituyen pequeñas ideas, pero también podemos encontrarnos con un maestro que nos ayude a separar el grano de la paja. Ese es el verdadero proceso educativo.

Entre las mujeres que viajan a América las hay que marchan únicamente por acompañar a sus maridos y las hay inquietas y emprendedoras como aquellas que, entendiendo el importantísimo papel de la mujer educadora, van a servir de maestras a las niñas indias, mestizas y criollas. Las hay también piadosas que dejan los tranquilos monasterios españoles y cruzan los mares para que las

\footnotetext{
${ }^{27}$ Muraro, op. cit., p. 42.
} 
mujeres en aquellas tierras puedan también dedicarse a Dios o a atender a los más necesitados. Llegan, pues, las maestras. En este proceso hubo varias etapas en las que es importante la monarquía, en concreto la emperatriz Isabel, como ha quedado dicho, esposa de Carlos I de España y V de Alemania, pero sin duda alguna el personaje fundamental fue Zumárraga.

Este santo y docto obispo, pronto se dio cuenta de que las mujeres indígenas eran, ante todo, objeto de tributo por parte de sus padres, quienes las otorgaban como regalo a cambio de favores variados. Comprobó que se producía, por tanto, un auténtico tráfico y explotación; que se conculcaba la dignidad de las niñas tratándolas como a cosas. ¿Qué era si no la poligamia? ¿Qué era si no el hecho de que fueran ellas las que sacaban adelante la familia con el trabajo de sus propias manos? Vista la situación, este gran hombre impulsó ardientemente la batalla para que las cosas cambiaran. La batalla no era otra que la educativa. Con otros franciscanos, pidió a la Corona que enviaran maestras para no sólo formar culturalmente y cristianamente a las autóctonas, sino para hacerlas conscientes de su propia dignidad, aunque eso requiriera el enfrentamiento con sus padres. Estas cuestiones solicitan un estudio más amplio sobre esta figura señera en la América española: una nueva visión de Zumárraga. Pero veamos algunos aspectos de las órdenes Terceras en concreto, de la franciscana que sería la solicitada por Zumárraga para educar a las niñas indígenas.

Las órdenes Terceras nacen en la Edad Media de manera espontánea, dentro del clima de intensa espiritualidad cristiana propio de la época. Algunos seglares piadosos buscaron una forma de afiliación o especial relación con las grandes casas religiosas que entonces eran, por lo común, las Abadías. Así nació la «Oblación benedictina», extendida a las Abadías de las órdenes monásticas. Pero el origen propiamente dicho de las T. ó. se encuentra en S. Francisco de Asís, quien hacia el 1212 comenzó a admitir seglares que, sin abandonar su propio género de vida, se incorporaban de alguna forma a la Orden franciscana.

La Terciaria franciscana se extendió por todo el mundo, al compás de la difusión de las dos primeras órdenes. Aprobada por Honorio III, se vio enriquecida por grandes privilegios y grandes recomendaciones de otros muchos Papas. Esta idea de unir seglares a una Orden religiosa encontró pronta aceptación en las demás órdenes mendicantes. Así, hacia 1220-25 hay indicios y pequeños grupos de hermanos y hermanas de la «Milicia de Jesucristo», Congregación promovida por los dominicos para secundar sus fines y particularmente el de luchar contra la herejía. En 1285 el maestro general Fray Munio de Zamora reelaboró la Regla de esta Milicia, acomodándola al tipo de la Tercera Orden. Más tarde, la Santa Sede concedió expresamente a las órdenes religiosas la potestad de agregarse asociaciones de esta clase: a los dominicos, en 1406; a los agustinos, en 1409; a los servitas, en 1424; a los carmelitas, en 1452; a los mínimos, en 1508; a los trinitarios y premonstratenses, en 1751. De esta manera vino a re- 
sultar normal que una Orden religiosa de algún prestigio tuviese, además de la correspondiente rama femenina, su Tercera Orden Secular.

El Código de Derecho Canónico, en la parte tercera del libro II, consagrado a «Los laicos», regula lo referente a las asociaciones de fieles en general (título XVIII) y en particular (título XIX). El can. 700 dice que «en la Iglesia se distinguen tres clases de asociaciones: terceras órdenes seculares, cofradías y pías uniones», estableciendo, al tratar del orden de precedencia, una cierta jerarquía entre ellas, puesto que prescribe que precedan las Terceras órdenes a las demás asociaciones. Define después a los terciarios seculares diciendo que son quienes «viviendo en el siglo, bajo la dirección de alguna Orden y conforme al espíritu de la misma, se esfuerzan por adquirir la perfección cristiana de una manera acomodada a la vida en el siglo, según las reglas para ellos aprobadas por la Sede Apostólica». Aparece clara en esta definición la principal característica de las Terceras órdenes: dependencia de una Orden religiosa, a la que jurídicamente están subordinadas y de quien reciben la orientación espiritual, acomodada a la vida en el siglo.

Características muy acusadas de la espiritualidad de las Terceras órdenes son, de una parte, la dependencia de una Orden religiosa y, de otra parte, la permanencia del terciario en el mundo. Se trata, por consiguiente, de que un seglar busque la perfección cristiana impregnándose del espíritu propio de una Orden religiosa, secunde sus actividades apostólicas, se familiarice con lo que le caracteriza dentro de la Iglesia, etc. Según Chesterton, la orden tercera fue pensada para ayudar a la gente corriente a ser corriente con una exultación fuera de lo corriente».28

El influjo que las órdenes religiosas alcanzaron por medio de sus respectivas Ordenes Terceras en la historia de la espiritualidad cristiana es imposible de valorar. Las Ordenes Terceras, y muy en especial la franciscana, suscitaron reiterados movimientos de espiritualidad. Iniciada en tiempos del mismo S. Francisco, alcanzó una gran difusión, siguiendo la Regla del Papa Nicolás IV, con algunos comentarios o retoques de otros varios Papas (Julio II, Clemente VII, Paulo III, Inocencio XI) hasta León XIII, que puso al día la antigua Regla y promulgó nuevas disposiciones en la Bula Misericors Dei Filius de 30 de mayo de 1883. Contemporánea a la franciscana puede considerarse la dominicana, similar a aquella.

Ambas órdenes terciarias se desarrollaron ampliamente en la América española y fueron responsables en gran medida de la educación femenina. Y es que esta comprendía, además de la lectura y escritura, lo que era la preparación para ser señora de su casa, esposa y madre, lo cual se denominaba «regir la casa». ${ }^{29}$ Y todo ello en el marco de la evangelización.

\footnotetext{
${ }^{28}$ San Francisco de Asís. Madrid, Homo Legens, 2006, p. 81.

${ }^{29}$ Recopilación de las Leyes de los reinos de las Indias, facsimil de la cuarta impresión de Madrid, 1791, Consejo de la Hispanidad, Madrid, 1943, libro I, tit. III, ley XIX.

Hispania Sacra, LXIV

129, enero-junio 2012, 211-235, ISSN: 0018-215-X, doi: 10.3989/hs.2012.007
} 
En este sentido, abordar los saberes cotidianos, que están más en la experiencia de las mujeres que en la de los hombres, se hace visible y se presenta como objeto de aprendizaje. Los saberes que aplicamos de manera permanente en nuestra vida, en la mayor parte de los casos elaborados y transmitidos por mujeres, que son fundamentales para la calidad de nuestra vida, pero que son invisibles y que están excluidos del bagaje de conocimientos dignos de ser enseñados: la alimentación y los saberes que implica; los cuidados que necesita una persona cuando está enferma; el cuidado de los espacios comunes; el valor de las relaciones, etc.

Así pues, la enseñanza elemental de las niñas en América guarda una relación directa con las necesidades de la vida cotidiana y la evangelización. En este último ámbito se produjo una colaboración muy estrecha entre la Iglesia y el Estado, en su misión de evangelizar los nuevos súbditos. Como señala González Rodríguez, esa colaboración «proporcionó al Estado, casi gratuitamente, un número considerable de inculturadores dispuestos a elevar, con miras a la expansión de la fe cristiana, el nivel cultural de los nuevos súbditos americanos, lo que facilitaría su inserción en las estructuras estatales». ${ }^{30}$ Continúa señalando que en el siglo XVIII no quedaba en la geografía de Hispanoamérica pueblo o rancho donde faltase escuela.

Esa formación básica fue ejercida sobre todo por los misioneros, doctrineros y sacerdotes, que instalaban sus escuelas a la sombra de la misión. Se perpetuaba así la tradición europea de las escuelas monacales como centros de cultura literaria, artesanal y agrícola. Desde 1503 se había ordenado que los misioneros debían tener una casa donde, además de la catequesis, se enseñara a leer y escribir a los niños. Así lo indicaba en una real orden al gobernador Ovando la reina Isabel, mandando que en cada pueblo que se fundara debía levantarse junto a la iglesia una casa donde el capellán enseñara a los indígenas lectura, escritura y a santiguarse. Señala Borges ${ }^{31}$ que no debió ser muy estricto el cumplimiento de este mandato, y que en las Leyes de Burgos se especificaba que era obligación de los encomenderos entregar a los franciscanos todos los hijos de caciques menores de trece años para que aprendiesen a leer, escribir y la doctrina cristiana. La enseñanza debía durar cuatro años, y después los niños volverían a su lugar de procedencia para servir de maestros.

Aunque no estaban tan definidas como en la actualidad las fronteras entre los diferentes niveles de enseñanza, podemos considerar que la enseñanza primaria se centraba en primeros conocimientos de lectura, escritura y cuentas, y se aplicaba en escuelas de régimen externo o en internados. Muchas veces en las propias escuelas se elaboraban gramáticas y catecismos en lengua indígena, lo que ofrece una muestra del ingente trabajo educativo que desempeñaron esos

\footnotetext{
${ }^{30}$ González Rodríguez, J. en Borges, P.: La Iglesia y la Evangelización, Madrid, 1991, p. 716.

${ }^{31}$ Historia de la Iglesia en Hispanoamérica y Filipinas, 2 vols., Madrid, BAC, 1992.
} 
misioneros/as que ejercían de maestros. Incluso en algún convento existió cátedra de lenguas indígenas.

A esto se sumó la enseñanza de las artesanías que las mujeres españolas practicaban. Las indígenas sabían hilar el algodón y el ixtle, pero no el lino, ni la lana. Hubo una orden de la reina Isabel a la Segunda Audiencia mandando que las mujeres de la Nueva España hilaran la lana. ${ }^{32}$ Para enseñar todo esto las maestras llevaron a América los elementos necesarios tales como hilos, agujas, tijeras, etc., y con todo ello se fue enriqueciendo la artesanía nativa produciéndose un hermoso mestizaje artesanal que aún se halla vivo en prácticamente toda la geografía hispanoamericana.

Preparar a las mujeres para estas labores se consideró parte importantísima en la educación, pues con ello ampliaban el medio de sostenimiento para ellas y sus familias. Por esto en los edificios de todas las instituciones femeninas hubo siempre como elemento esencial, una sala de labores, ya que una de las formas «apropiadas» de estar en el mundo para las mujeres es su opción por el saber de la experiencia, el saber contextual, en contacto con lo concreto. Esa preferencia por el saber de la experiencia, cuando se traduce en materiales, facilita ofrecer lo que en otro lugar hemos llamado el «conocimiento encarnado»; ${ }^{33}$ es decir, presentan el conocimiento ligado siempre a las personas, no desvinculado de sus experiencias, sus necesidades.

\section{DOS MUJERES SINGULARES}

En este proceso, me interesa destacar a Catalina Bustamante y a Juana Velásquez por lo que se verá a continuación. La primera era terciaria franciscana, es decir de la misma orden que Zumárraga. Doña Catalina y su marido, Diego Tinoco, extremeños de origen, habían llegado a Santo Domingo en 1514 con sus dos hijas, sus dos sobrinas y un yerno. Años después la encontramos en la Nueva España con las hijas y el yerno. De los demás no se sabe nada. Catalina, según Zumárraga, era mujer «honrada, honesta y virtuosa y persona de muy buen ejemplo».34 Esto es, la mujer que reunía las condiciones exigidas a quienes tuvieran una responsabilidad educativa.

Como primera maestra de la Nueva España, enseñó a las niñas indígenas un nuevo modo de vivir, más acorde con la dignidad humana. En lengua castellana, trasmitió una serie de valores culturales que abarcaban desde la manera de

${ }^{32}$ A. de Herrera, Historia General de los hechos de los castellanos en las islas y tierra firme del mar océano, Editorial Guaranda, Asunción del Paraguay, década IV, tomo V, libro VII, p. 354. Véase también Luque, E, y Saranyana, J.: La Iglesia Católica y América. Madrid, 1992.

${ }^{33}$ Blanco, 2006.

${ }^{34}$ «Carta del electo obispo de México del 27 de agosto de 1529». Cit. por Josefina Muriel en La sociedad novohispana y sus colegios de niñas, México, Universidad Autónoma, 1995, p. 56. 
vestir y comportarse hasta los rudimentos alfabéticos y aritméticos necesarios para manejarse en ese nuevo medio mixto que comenzaba en aquel momento, todo ello sin descuidar, como se señalaba antes, lo que hasta el momento se consideraba en el mundo conocido que era propio de una mujer: sus labores domésticas. Y el cristianismo fue el sustrato en el que se desarrolló esta educación ya que era la religión que propugnaba «primero hombres y después cristianos», es decir, primero conscientes de haber sido creados por Dios con un intelecto y una voluntad que los/las hacía diferentes a los animales y, por ello, con unos comportamientos también diferentes a los de estos.

Se puede decir de ella y de otras maestras que trabajaron con «pasión por hacer viable a cada una y a cada uno, atención a la singularidad de cada alumna y cada alumno, concretos y singulares. Ese es el principio básico de la educación. Lo que se descubre con estas maestras es que «sus enseñanzas sirven para la vida, es decir, para que cada criatura pueda seguir creando su propia singularidad y con su capacidad y, así cada cual vaya dejando en el mundo la huella de su presencia insustituible». ${ }^{35}$

Apego a la realidad, saber adaptarse a cada situación concreta y cambiante y elaborar una teoría pedagógica a partir de la experiencia». Ése es un camino distinto al que sigue el pensamiento académico, que es masculino: la teoría pedagógica se desliga de la experiencia pretendiendo convertirla en conocimiento científico, válido para todo y para todos gracias a que se le despoja de lo concreto, de todo lo que lo conecta con realidades contextuales y singulares. Pero no es exactamente así porque es el amor el que ayuda a la clarividencia al arte de la mediación, ese don para crear vínculos donde hacen falta; mediación que sólo es posible amando la relación, buscándola, también en lo que tiene de conflicto.

Señala Josefina Muriel, ${ }^{36}$ que esta maestra -Catalina Bustamante- amó a sus discípulas tanto que ante el ultraje que sufrieron dos de ellas por parte de un tal Juan Peláez de Berrio quien encargó secuestrarlas, reaccionó denunciando enérgicamente el asunto ante Zumárraga primero y, por carta, ante el mismo rey después. La misiva, por ausencia de Carlos I, llegó a manos de la emperatriz que ejercía de regente en aquel momento, y que cursó de inmediato órdenes a las autoridades mexicanas para que intervinieran, $\mathrm{y}$ a las niñas y maestras «no se les hiciera agravio alguno», ${ }^{37}$ es más, les pedía que se las ayudara en todo lo que necesitaran.

A esta valiente terciaria franciscana no le bastó ser fundadora del primer colegio para niñas indígenas, ni protestar por los atropellos que aquellas sufrían, sino que, consciente de la importancia que tenía la educación, marchó a España en 1535 y se presentó ante el Consejo de Indias para pedir más maestras. Ella

\footnotetext{
${ }^{35}$ Montoya, 2005: 204.

${ }^{36}$ Ibid, p. 57.

${ }^{37}$ AGI. Audiencia México, 1088-I, real cédula al electo Zumárraga, Toledo, 24 de agosto de 1529.
} 
misma se encargó de proponer a otras tres terciarias para la labor educativa americana, que fueron respaldadas de nuevo por la emperatriz y después de ser convenientemente investigadas en su vida y costumbres marcharon a la Nueva España con Catalina.

Con respecto a Juana Velásquez, además de su brillante trabajo en el marco de la educación indígena, -podríamos repetir todo lo dicho para Catalina de Bustamante- hay que reseñar la actividad que desarrolló para conseguir el inmueble apropiado para una buena educación. En este sentido, en 1532 se quejó ante la reina de las molestias que les causaban, a ella y a todas las demás, maestras y discípulas, la presencia constante de trabajadores dentro del claustro del colegio. Reclamaba una casa adecuada para vivir con la honestidad debida $\mathrm{y}$, ya que las obras tardaban tanto, que se les permitiera pedir limosna para que cuanto antes se concluyeran. La reina no concedió el permiso, pero recomendó a la Audiencia que dichas obras se agilizaran. ${ }^{38}$

Las obras se aceleraron, efectivamente, y el colegio desde 1531 es mencionado en los documentos como de La Madre de Dios, también aparece como monasterio de beatas. Sabemos que fue amplio porque acogía a más de 400 niñas, amén de las maestras y las clases correspondientes a las distintas materias que allí se cursaban: labores, clases teóricas, y la capilla, que toda entidad del carácter que fuere, especialmente las educativas, requería para la correspondiente instrucción en el cristianismo.

También se comprobó la necesidad de formar maestras indígenas. En este sentido son claras las palabras de fray Bernardino de Sahagún: ${ }^{39}$ "Ya las que nos parecía que estaban bien instruidas en la fe y eran matronas de buen juicio, las hicimos preladas de las otras para que las rigiesen y enseñasen en las cosas de la cristiandad y de todas las buenas costumbres». Lógicamente, al tratarse de indígenas como ellas, las niñas las sentirían más cercanas, más comprensivas y, es de suponer, que las obedecerían con más gusto y prontitud. Pero el vehículo educativo por antonomasia fue sin duda la familia y el mestizaje que se produjo en su seno.

\section{Algunos apuntes sobre la asistencia social femenina}

Como en todos los territorios del occidente cristiano antes de las revoluciones contemporáneas, la gran responsable de lo que hoy llamaríamos solidaridad fue la Iglesia Católica. Ha sido desde siempre la Iglesia el primer agente asistencial a escala planetaria: hospitales, niños abandonados, ancianos, escuelas,

\footnotetext{
${ }^{38}$ AGI Audiencia México, real cédula al presidente y oidores. Madrid, 27 de noviembre de 1532.

${ }^{39}$ Historia de las cosas de la Nueva España, Mexico, Pedro Robredo, 1938, Tomo III, Libro X, Cap. 27, p.83.
} 
presos... A través de las parroquias y las Órdenes religiosas (mercedarios, hospitalarios, franciscanos, etc.), la Iglesia ha sostenido con sus propios bienes y recursos el peso de la asistencia social, asumiéndola como parte de su mensaje salvador, sobre todo en épocas, por ejemplo el medievo y, por supuesto, la Edad Moderna a la que yo me dedico, en las que el Estado, como agente social, era prácticamente inexistente o que, conscientemente, delegaba en ella.

Incluso en el siglo XIX, cuando los gobiernos liberales intentaron centralizar y secularizar las redes asistenciales mediante la desamortización de bienes eclesiásticos (por ejemplo las de Mendizabal y Madoz en España), a pesar de las pérdidas y de la persecución del derecho de asociación, la Iglesia siguió manteniendo su labor social a través de lo que dio en llamarse catolicismo social, surgido del magisterio de León XIII: sindicatos, escuelas, montepíos, orfanatos, etc.

Hoy mismo, gran parte de las ONGs que operan en el mundo son o han sido de identidad cristiana, y un buen número de voluntarios tiene en su trabajo una fuerte motivación de tipo religioso. La realidad -guste o no admitirlo- es que conceptos como los de ayuda social, solidaridad o atención a los más necesitados tienen sus verdaderas -y únicas- raíces en el cristianismo.

Fue esta institución quien impulsó la construcción, mantenimiento y actividad de hospitales, asilos, casas de recogida y un largo etcétera, que desarrollarían su labor por todo el territorio americano. En el caso del Nuevo Mundo, esta labor se vio beneficiada por la estrecha colaboración mantenida con la Corona, que financiaría en gran parte todas estas obras.

Pero la importancia de la tarea va mucho más allá de la mera financiación o puesta en marcha de este tipo de actividades. La entrega abnegada de tantos hombres de Iglesia que dejaron muchos años de su existencia $-\mathrm{y}$ en numerosas ocasiones la propia vida- atendiendo las necesidades de los pobladores de América, fueran de ascendencia europea o indígena rebasa con mucho la misión impulsora de la Corona, aunque esta, por su parte, empujaba siempre la creación de este tipo de instituciones, y en el trazado de cada nueva ciudad se incluía siempre el espacio destinado a hospital.

Pablo Lorenzo Laguarta citando a José Vasconcelos afirma que las heridas que abrieron en carnes indias los conquistadores, con el filo de su espada las cerraron y curaron, con sus plantas, los misioneros. Y es que ciertamente fueron los misioneros quienes lograron con su actividad incansable a favor del indio y con su dedicación a labores de beneficencia poner de manifiesto la verdadera intención de la Corona con respecto a los súbditos americanos que se incorporaban a la Monarquía Hispánica.

Por otra parte, las hermandades y cofradías han ocupado un papel destacado en el campo asistencial, constituyendo uno de los elementos más activos. Mo- 
vidas por ese espíritu cristiano al que aludíamos antes, de hermandad y solidaridad, las cofradías plasmaron su labor benéfica de forma sencilla, tanto en lo espiritual como en lo material. Muchos autores están de acuerdo en concluir que la labor asistencial fue la principal actividad de las cofradías.

Tres aspectos destacan especialmente en la labor asistencial de las cofradías y hermandades de la época moderna, tanto en Europa como en América:

1. Los mecanismos de previsión: una cotización por parte del cofrade y una prestación por parte de la cofradía en caso de pobreza, hasta el punto de que, como comenta Rumeu de Armas, «en la Sevilla de los RR CC casi todos los trabajadores estaban asegurados contra los riesgos de enfermedad y accidente».

2. La asistencia hospitalaria, incluida en las medidas de previsión porque ya conocemos la precariedad de la vida del hombre en la Modernidad, la enfermedad era habitual, por eso es muy frecuente ver en los estatutos de las cofradías normas como las siguientes: velar al hermano enfermo que lo pidiere o a sus hijos (tengamos en cuenta que la mortalidad infantil era muy elevada); visitar al hermano, preocuparse de que el hermano enfermo recibiera, además de alimento y medicinas, los sacramentos de la confesión y comunión, etc. La labor asistencial de un hospital era a menudo múltiple, leo textualmente de los estatutos de la Cofradía y hospital de la Caridad de Granada: «socorrer todo género de necesidades de pobres vivos y difuntos, exercitando las obras de caridad y misericordia, vistiendo desnudos, curando enfermos, sacando presos de la cárcel, rescatando cautivos, casando huérfanas o enterrando muertos. Así ajusticiados como ahogados en los ríos y de otras muertes desastrosas o naturales, tan desamparados que no tuviesen caudales o deudos que los socorriesen». En realidad, el mundo de la pobreza en todas sus manifestaciones era el destinatario de la labor hospitalaria de cofradías y hermandades.

3. La solidaridad ante la muerte. Y es que las prácticas benéficas se entendían como derivación directa del precepto cristiano de la caridad, que de forma programática se explicitaba así en una cofradía: «han de amarse como verdaderos hermlos unos los trabajos de los otros» (Cap. 14 de la Regla de la Hermandad de Animas de la parroquia de San José de Granada). En este sentido, socorrer al pobre y al necesitado es una obligación evangélica, que se repite tanto en los Padres de la Iglesia como en los tratadistas filosófico-teológicos. Es una obligación de todo cristiano. Por ello, en el seno de las hermandades y cofradías debe considerarse como uno de sus fines o funciones explícitas, por cuanto la caridad con los hermanos va indisolublemente unida al amor de Dios. O sea, culto y asistencia han de ir unidos. Son las dos caras de una misma moneda. Veamos algunos ejemplos. 
Es destacable la presencia femenina en la cofradía de Nuestra Señora de la Misericordia (siglo XVII) en IRAPUATO, término de Guanajuato. En los Estatutos, $\mathrm{n}^{\mathrm{o}} 11$ concretamente, se admite a las mujeres como hermanas, asunto este no muy generalizado en aquel tiempo en el que ellas habitualmente no eran titulares, pudiendo gozar en este caso de los mismos beneficios que los hermanos y realizar las mismas tareas o más.

Con respecto a la Cofradía del Santísimo Sacramento de Méjico, tengo datos de cómo en 1538, es decir apenas llegados los españoles a la Nueva España, ya está fundada con los fines de usar misericordia hacia los pobres, casar huérfanas y socorrer viudas. Encargadas de los trámites concretos están las mujeres de la cofradía, que no se dice que sean hermanas pero que se encargan fundamentalmente ellas de estos menesteres.

El año 1548 se fundó en México el colegio de la Caridad por iniciativa de esta cofradía del Santísimo. ${ }^{40} \mathrm{Su}$ fundación se produce por acuerdo de un grupo de vecinos mexicanos para promover el culto eucarístico en las fiestas del Corpus Christi y del Jueves Santo, velar al Santísimo en la catedral y acompañar al sacerdote cuando lo llevaba por la ciudad para los enfermos; además se proponían el ejercicio de obras de caridad, con enfermos, pobres y moribundos, como hemos señalado más arriba.

Gobernaba la cofradía una Junta elegida anualmente por votación de los miembros. Al fundar el colegio de la Caridad se propuso la cofradía atender a la formación de la mujer mexicana. Inicialmente acogió a niñas mestizas, que en esas fechas abundaban en la capital de la Nueva España; posteriormente se dedicó a educar a las criollas. El colegio de la Caridad fue el primer colegio para la mujer de la ciudad de México y posiblemente de América continental; también se contaría entre los primeros centros educativos femeninos europeos.

El grupo fundador del colegio, ${ }^{41}$ proyectó y llevó a cabo el establecimiento del colegio de la Caridad con un plan que abarcaba todas las fases necesarias para hacer realidad la empresa: plan financiero, proyecto pedagógico y planteamiento jurídico, dotándolo de los medios encaminados a esos tres ámbitos del funcionamiento institucional.

Fue iniciado con los bienes donados por los cofrades, a los que se sumaron los que le llegaron del patronato de la corona, y los legados de quienes deseaban colaborar en esta labor asistencial. Con estos ingresos se sostuvieron treinta be-

${ }^{40}$ AGN, Cofradías, 10: México. Domingo de la Santísima Trinidad, Junio 16 de 1538. Copia de la Fundación de la Ilustre Archicofradía del Santísimo Sacramento, que en dicho año, se fundó en esta Santa Iglesia Catedral Metropolitana: como también de la del Colegio de Nuestra Señora de la Caridad, alias de las Niñas, y sus constituciones, cuyo Patronato, y dirección pertenece a la expresada Archicofradía. Un buen estudio de la Cofradía lo encontramos en Bazarte Martínez (1989).

${ }^{41}$ Luque Alcaide, E.: Iglesia en América Latina (siglos XVI-XVIII) continuidad y renovación. Madrid, Eunsa, 2008. 
cas destinadas -en un principio- a huérfanas que carecían de medios de fortuna. Fue una iniciativa privada e independiente de las autoridades virreinales. Así quedó configurado en las constituciones del colegio. ${ }^{42}$ En ellas aparece como un centro laical, regido por una Junta formada por el Rector, los diputados y el mayordomo de la cofradía.

La Junta de gobierno disponía de amplias competencias: nombraba a la rectora por un trienio -siempre debería ser seglar, ya viuda o soltera- y podían reelegirla si lo consideraban oportuno; nombraban también a las demás personas que atendían la casa y colegio: maestras, oficialas y asistentas; aprobaba la admisión de las colegialas y supervisaba el funcionamiento del colegio. Las constituciones prescribían también que la Junta realizase anualmente una visita del colegio para comprobar si se vivían las constituciones. ${ }^{43}$

El planteamiento educativo tenía tres objetivos: el aprendizaje de la doctrina cristiana y de la lectura; ${ }^{44}$ el dominio de los trabajos del hogar; y una formación moral centrada principalmente en las virtudes de la piedad, el ejercicio de la caridad y el hábito de la laboriosidad. La formación moral aparece en las constituciones del colegio como meta formativa prioritaria. ${ }^{45}$

De otra parte, aunque las autoridades civiles no habían interferido en el gobierno del centro, la Real Cédula de 1552 prescribía que anualmente el virrey realizase la visita del colegio. Pero los fundadores del Colegio para garantizar que el colegio se mantuviese a lo largo del tiempo tal como lo habían fundado, estudiaron y pusieron en marcha una solución difícil pero que se les aparecía pertinente al caso: la de vincularlo al patronato de la Archibasílica romana de San Juan de Letrán, aplicando la figura de la agregación a las basílicas romanas. Así pues, en el último tercio del siglo XVI, hallamos en México, un centro educativo para la mujer que, por la acción de sus fundadores, gozaba de autonomía de gobierno frente a los poderes civiles y eclesiásticos novohispanos.

Es destacable la Obra pía de Leonor de Sandoval, a favor de doncellas pobres en la ciudad de México. Así como la de Inés Muñoz, cuñada del conquistador del Perú Pizarro, que legó en aquellas tierras una importante cantidad de dinero para auxilio de los indios. Leonor Portocarrero y su hija fundaron en Lima una casa de las llamadas de Recogimiento para huérfanas y niñas de la calle. Isabel de Porras fundó también en Lima un colegio para pobres.

En fin, no se trata de seguir por este camino porque los ejemplos se multiplican. Vayamos, pues, resumiendo. A la mujer, circunscrita durante siglos a la casa y al ámbito de lo privado, se le adjudicaron unas cualidades (intuición,

\footnotetext{
${ }^{42}$ Luque Alcaide, E.: Colegio de la Caridad, primer establecimiento educativo para la mujer en el México virreinal. Estudio de sus constituciones. Sevilla, Suplemento del AEA, 1990, pp. 3-25.

${ }^{43}$ Ibid., p. 23: Constitución n. 30.

${ }^{44}$ Ibid., p. 23: Constitución n. 30.

${ }^{45}$ Ibid., pp. 10-14. 
amor por lo concreto, cuidado de los detalles, espíritu de servicio para atender a las personas singularmente, etc.) que han consagrado «el eterno femenino»y que no dejan de ser un tópico. No obstante es posible que el tópico obedezca, antes de haberse enquistado y falseado, a una realidad más original y profunda.

En efecto, no parece descabellado suponer que la peculiar relación que la mujer guarda con la vida haya generado en ella unas disposiciones particulares. Al reflexionar sobre su forma de vivir y sobre las funciones que ha desempeñado durante tantos siglos se entiende que haya desarrollado especialmente determinados hábitos intelectuales y capacidades: aquellos que tienen que ver directamente con la práctica. Frecuentemente su conocimiento se ha movido dentro del ámbito de lo que llamamos experiencia, puesto que, además, se le negó el acceso a la formación intelectual y al conocimiento científico.

Esto explicaría, por ejemplo, ese curioso fenómeno de la «intuición femenina», ese «ver» sin necesidad de discurso, esa inteligencia, que yo denomino «poliédrica», ${ }^{46}$ porque es capaz de tener en cuenta todos los planos de la vida humana: no sólo los intelectivos sino también los afectivos, que en tantos momentos condicionan de forma mucho más intensa a la persona. Por contraste, el hombre habría desarrollado, también durante generaciones, hábitos intelectuales más abstractos, los propios de la ciencia, no relacionados directamente con la vida. La cuestión es que ella ha ejercitado «el cuidado y la conservación», ${ }^{47}$ conceptos que hoy son altamente valorados en el ámbito de la asistencia social, porque la sociedad actual ha generado, con su extremado individualismo y su consumismo exacerbado, bolsas ingentes de soledad y pobreza. Preciso es, pues, rentabilizar ese superavit de experiencia femenina, y la prueba palpable es que en algunas ONGs actuales las mujeres son más del $70 \%$.

\section{A MODO DE CONCLUSIÓN}

Es verdad que los abusos fueron muchos y grandes, pero ninguna legislación colonial extranjera es comparable a las Leyes de Indias promulgadas por la Monarquía española. ${ }^{48}$ Por ellas se prohibió la esclavitud, se proclamó la libertad de los indios, se les prohibió hacerse la guerra, se les brindó la amistad de los españoles, se reglamentó el régimen de Encomiendas para castigar los abusos de los encomenderos, se instituyó la instrucción y adoctrinamiento de los indios como principal fin de los Reyes de España, se prescribió que las conversiones

\footnotetext{
${ }^{46}$ Bel Bravo, M. A.: La mujer en la Historia. Madrid, Encuentro, 1998.

${ }^{47}$ Ballesteros, J.: Postmodernidad, decadencia o resistencia. Madrd, Tecnos, 1988.

${ }^{48}$ Véase también el Testamento de Isabel la Católica. Está publicado por muchos autores. Puede verse Bel Bravo. M. A.: Textos para la Historia de las Mujeres. Barcelona, Ariel, 2000, pp. 103-121.
} 
fueran voluntarias y se transformó la conquista de América en difusión del espíritu cristiano. ${ }^{49}$

«Asimismo se les iba preparando (a los indios) a su autosostenimiento: se enseñaba no sólo la doctrina cristiana y la vida moral y honesta sino también los oficios y artes manuales. De allí salían diestros los nativos como alarifes, carpinteros, doradores, zapateros, sastres, músicos, herreros, labradores, pescadores de ríos, etc. Los beneficiados eran los antiguos indómitos mobimas, churimanas, cayubas, guarayos, tapacuras y baures».$^{50} \mathrm{La}$ educación impartida por mujeres, así como la asistencia social, también atendida por ellas mismas en un alto porcentaje, junto a la relevancia indudable de la religiosidad popular, configuraron un mestizaje cultural sin parangón con otros países igualmente colonizadores.

Asimismo, el estudio del microcosmos familiar, planteado como punto de referencia para el análisis de los cambios del occidente euroamericano durante la época moderna, cuyo elemento decisivo algunos historiadores han creído hallar en el -tan llevado y traído- «individualismo afectivo», requiere un nuevo enfoque. A la luz de las recientes investigaciones, parece preciso reconsiderar este tema para comprender cómo sucedieron en realidad tales cambios.

\section{BiBLIOGRAFÍA CITADA}

Ballesteros, J. 1988. Postmodernidad, decadencia o resistencia. Madrid, Tecnos.

Bel Bravo, M. A. 1998. La mujer en la Historia. Madrid, Encuentro.

Bel Bravo. M. A. 2000. Textos para la Historia de las Mujeres. Barcelona, Ariel, 2000.

Bel Bravo, M. A. 2000: La familia en la Historia. Madrid, Encuentro.

Bodino, 1576. Los seis libros de la República, París. Ed. Bravo Gala, P.1985: 9-19. Madrid, Tecnos.

Borges, P. 1992. Historia de la Iglesia en Hispanoamérica y Filipinas. Madrid, BAC.

Casey, J. 1983, Historia de la familia, Valencia.

Chesterton, G. K. 2006. San Francisco de Asís. Madrid, Homo Legens.

Díaz del Castillo, B. 1984: Historia verdadera de la conquista de la Nueva España. Madrid, Historia 16.

González de Cellorigo, M. 1991: 63. Memorial de la política necesaria y útil restauración a la república de España y estados de ella, y del desempeño universal de estos reinos, Valladolid, 1600. Ed. José Luis Pérez de Ayala, Madrid, Instituto de Estudios Fiscales.

González Rodríguez, J. 1991: 716, en Borges, P.: La Iglesia y la Evangelización, Madrid. Guerra, F. J. 1982. México: del Antiguo Régimen a la Revolución, México, FCE.

Henry, L. 1953: 281-290 «Une richesse démographique en friche: les registres paroissiaux», en Population, VIII.

\footnotetext{
${ }^{49}$ González de Cellorigo, Martín, op. cit., p. 99.

${ }^{50}$ Nieto Vélez, A.: La primera evangelización en el Perú. Madrid, 1992, p. 204.
} 
Herlihy, D. 1985: 223-245: «Avances recientes de la demografía histórica y de la historia de la familia», en VV. AA.: La Historiografía en Occidente desde 1945. Actitudes, tendencias y problemas metodológicos. Pamplona, EUNSA.

Herrera, A. de, 1992: 354, Historia General de los hechos de los castellanos en las islas y tierra firme del mar océano, Editorial Guaranda, Asunción del Paraguay, década IV, tomo V, libro VII.

Hildebrand, 1997. El Corazón. Madrid, ediciones Palabra.

Hirschberg, J. 1979 «Social experiment in New Spain: a prosopographical study of the early settlement at Puebla de los Ángeles 1531-1534».

Hispanic American Historical Review, vol. 59, $\mathrm{n}^{\circ} 1$.

Konetzke, 1953. Consulta del Consejo de Indias. Madrid 20 de junio de1596.

Lavrin, A. 1994. Historia de las mujeres latinoamericanas, México, Siglo XXI.

Luque Alcaide, E. 1990. Colegio de la Caridad, primer establecimiento educativo para la mujer en el México virreinal. Estudio de sus constituciones. Sevilla, Suplemento del AEA.

Luque, E, y Saranyana, J. 1992. La Iglesia Católica y América. Madrid, editorial Mapfre-América.

Luque Alcaide, E. 2008 Iglesia en América Latina (siglos XVI-XVIII) continuidad y renovación. Madrid, Eunsa.

Maura, J. 1995. «Mujeres hispanas en la conquista del Nuevo Mundo: a la vanguardia de los acontecimientos».

Revista de Estudios Hispánicos, año 22, 188.

Messori, V. 2000. Leyendas Negras de la Iglesia. Barcelona, Planeta.

Morales Padrón, F. 1974 en su libro Los conquistadores de América, 166. Madrid, Austral.

Muraro, L. 1994. «Autoridad sin monumentos», Duoda. Revista de estudios feministas, 7, 86-100.

Muriel, J. 2000. Cultura femenina novohispana. México, UNAM.

Nieto Vélez, A. 1992. La primera evangelización en el Perú. Madrid.

Olábarri Gortázar, I. y Caspistegui, F. J. (eds.) 1995: La «nueva» historia cultural, la influencia del postestructuralismo y el auge de la interdisciplinariedad. Madrid, Complutense. Actas.

Recopilación de las Leyes de los reinos de las Indias, facsimil de la cuarta impresión de Madrid, 1791, Consejo de la Hispanidad, Madrid, 1943, libro I, tit. III, ley XIX.

Rivera, M. 2004. Juana de Mendoza. Madrid, Ediciones del Orto.

Rivera, M. 2005. La diferencia sexual en la Historia, Valencia Publicaciones de la Universidad de Valencia.

Robredo, P. 1938. Historia de las cosas de la Nueva España, México.

Waldo, F. 1950. América Hispana. Buenos Aires.

VV. AA.: Las mujeres cambian la educación. 2008. Madrid. Narcea. 